\title{
A ZONA DE DESENVOLVIMENTO PRÓXIMO NA ANÁLISE DE VIGOTSKI SOBRE APRENDIZAGEM E ENSINO ${ }^{12} 3$
}

\author{
Seth Chaiklin \\ Tradutora: Juliana Campregher Pasqualini ${ }^{\Upsilon}$
}

Que tipo de ensino é mais efetivo para uma determinada criança? Sem dúvida, esta questão é imediatamente compreensível para qualquer professor comprometido de potencialmente qualquer país do mundo, e a ela a maioria dos professores provavelmente deseja respostas concretas, não apenas enquanto um problema teórico, mas também com relação às suas práticas. Se buscássemos na psicologia científica e na pesquisa educacional aconselhamento sobre esse problema prático, que tipos de resposta encontraríamos?

Essa simples questão levanta diversos e profundos problemas. Questões normativas e políticas relativas

aos objetivos do ensino e aos recursos disponíveis para concretizá-los devem ser resolvidas. É necessária uma teoria da aprendizagem que possa explicar como se desenvolvem as capacidades intelectuais. Se o ensino não é visto como um fim em si mesmo, então uma teoria sobre a relação entre o ensino de um determinado conteúdo escolar e suas consequências para o desenvolvimento psicológico se faz também necessária. Este último problema foi a principal tensão que levou Vigotski ${ }^{4}$ a desenvolver seu conhecido conceito de zona de desenvolvimento próximo ${ }^{5}$, o qual

1 Tradução do capítulo de livro: CHAIKLIN, Seth. The zone of proximal development in Vygotsky's analysis of learning and instruction. In: KOZULIN, A., GINDIS, B., AGEYEV, V. S., \& MILLER, S.M. (orgs.), Vygotsky's educational theory in cultural context. Cambridge University Press, 2003. Com autorização da Cambridge University Press.

2 Agradeço a Jacob Klitmøller e Svend Brinkmann pelo diálogo crítico sobre a formulação inicial da análise aqui apresentada, a Bert van Oers por convencer-me da necessidade de abordar a questão da imitação de modo mais explícito, e a Ray McDermott pela edição da versão final.

3 Meus agradecimentos a Shirley A. Campregher pelo valioso auxílio no processo de tradução e a Nádia Mara Eidt pela revisão do texto final. [N.T.]

* Professor e pesquisador do Departamento de Educação da University of Bath, Reino Unido. Autor do livro Radical-local teaching and learning (2005, Aarhus University Press, com Mariane Hedegaard), e organizador da coletânea Understanding practice (1993, Cambridge University Press, com Jean Lave). Presidente da International Society for Cultural and Activity Research (ISCAR) no período de 2002 a 2008.

II Psicóloga, Mestre e Doutora em Educação Escolar (Programa de Pós-Graduação em Educação Escolar da UNESP Araraquara). Professora Assistente do Departamento de Psicologia, Faculdade de Ciências, UNESP Bauru.

4 O nome de Vigotski tem sido grafado de diferentes formas na literatura científica ocidental, por tratar-se de outro alfabeto. Optou-se, nessa tradução, pela adoção da grafia Vigotski, que tem sido majoritariamente utilizada nas publicações em língua portuguesa; todavia, será preservada, nas referências bibliográficas, a grafia de cada edição, razão pela qual o leitor deparar-se-á com grafias diversas ao longo do texto. [N.T.]

5 O conceito zona blijaichego razvitia tem sido traduzido para o português de maneiras diversas: zona de desenvolvimento próximo, proximal, potencial, imediato. Zoia Prestes, em sua tese de doutoramento defendida em 2010 na Universidade de Brasília e intitulada "Quando não é quase a mesma coisa: Análise de traduções de Lev Semionovitch Vigotski no Brasil: Repercussões no campo educacional", esclarece os equívocos contidos na escolha dos termos proximal, potencial e imediato para tradução do conceito. O termo blijaichego significa, em russo, o adjetivo próximo no grau superlativo sintético absoluto, portanto: o mais próximo, proximíssimo. Zoia Prestes defende que a tradução que mais se aproxima do termo russo é zona de desenvolvimento iminente, cuja característica essencial, em suas palavras, é a das "possibilidades de desenvolvimento". Considerando o objetivo de divulgação científica, optou-se, na tradução do presente material, pela adoção do termo zona de desenvolvimento próximo, por tratar-se de expressão de maior familiaridade para o público de pesquisadores, estudantes e professores brasileiros, que, ao mesmo tempo, não conduz a compreensões equivocadas do conceito vinculadas a um suposto imediatismo/ obrigatoriedade ou nível potencial de desenvolvimento. [N.T.] 
focaliza a relação entre ensino e desenvolvimento, mas também se mostra relevante para muitos desses problemas. O conceito vigotskiano de zona de desenvolvimento próximo é mais preciso e elaborado do que no modo como tem sido comumente compreendido ou interpretado. O principal propósito desse capítulo é fornecer uma introdução e interpretação abrangentes desse conceito, tecendo comentários sobre as interpretações contemporâneas predominantes. Na conclusão do capítulo são apresentadas algumas perspectivas e implicações derivadas da interpretação [do conceito] aqui proposta.

\section{LOCALIZANDO A ZONA DE DESENVOLVIMENTO PRÓXIMO}

O termo zona de desenvolvimento próximo é provavelmente uma das mais amplamente conhecidas e difundidas ideias associadas à produção científica de Vigotski. Esse termo agora aparece na maioria dos manuais de psicologia do desenvolvimento e da educação, bem como em muitos livros de psicologia geral. No âmbito da pesquisa educacional, o conceito é agora largamente utilizado (ou citado) em estudos sobre ensino e aprendizagem em muitas áreas do conhecimento, entre elas, leitura, escrita, matemática, ciências, aprendizagem de uma segunda língua (e.g. Dunn \& Lantoff, 1998; Lantolf \& Pavlenko, 1995), educação moral (e.g. Tappan, 1998) e ensino do violino (Gholson, 1998); com diferentes populações de alunos, incluindo as assim chamadas crianças em situação de vulnerabilidade, com dificuldades de aprendizagem, portadoras de deficiência intelectual e com altas habilidades; com crianças pré-escolares (e.g. Smith, 1993) e com adultos (e.g. Kilgore, 1999); sobre tecnologias da informação e comunicação mediada por computador (e.g. Hung, 2001); sobre o uso de bibliotecas por crianças (McKechnie, 1997); em discussões sobre a formação de professores (e.g. Jones, Rua \& Carter, 1998; Torres, 1996) e sobre formação de profissionais de enfermagem (e.g. Spouse, 1998). O conceito também foi pinçado e utilizado de forma séria e substantiva em outras disciplinas acadêmicas e áreas profissionais, como a enfermagem (e.g. Holaday, LaMontagne \& Marciel, 1994), a psicanálise (e.g. Wilson \&
Weinstein, 1996), psicoterapia (e.g. Leiman \& Stiles, 2001) e terapia ocupacional (e.g. Exner, 1990; Lyons, 1984).

Embora o termo já tivesse aparecido na tradução de 1962 de Pensamento e Linguagem, foi primordialmente a aparição do capítulo VI de Formação social da mente (1978) que marcou a transição para uma atenção sustentada ao conceito por parte do público leitor de língua inglesa. No presente momento da história, o conceito, ainda que em uma forma relativamente simplificada, tornou-se conhecido entre pesquisadores voltados à educação. Assim, a maioria dos leitores desse capítulo já terá tido contato com algumas ou todas as frases frequentemente utilizadas para explicar ou definir o conceito, especialmente a definição do capítulo supracitado: "a distância entre o nível de desenvolvimento atual determinado pela resolução independente de problemas e o nível de desenvolvimento potencial determinado pela resolução de problemas sob orientação ou em colaboração com parceiros mais capazes" (Vygotsky, 1987, p.211; 1998b, p.202).

A popularidade, não obstante, tem seu preço. Wertsch (1984) sugeriu que, caso esse constructo teórico não fosse melhor elaborado, haveria o risco de ele ser "utilizado de forma imprecisa e indiscriminada, tornando-se assim tão amorfo que perderá seu poder explicativo" (p.7). Mercer e Fischer (1992) acreditam que "existe um risco que o termo seja usado como pouco mais do que uma alternativa da moda à terminologia piagetiana ou ao conceito de QI para descrever diferenças individuais de desempenho ou potencial" (p.342). Palinscar (1998) sugere que no contexto da pesquisa sobre a natureza negociada do processo de ensino e aprendizagem, este é "provavelmente um dos mais utilizados e menos compreendidos constructos teóricos na literatura educacional contemporânea" (p.370).

Pergunta-se, então: o que significa a famosa frase da página 86 ? Raramente se encontram outras fontes citadas ou discutidas em relação à zona de desenvolvimento próximo a não ser esse texto de 1978, com um eventual complemento de Pensamento e Linguagem (1987). Seria essa a única ou a principal definição? O conhecimento atual sobre a zona de desenvolvimento próximo reflete essencialmente tentativas de interpretar esses fragmentos textuais, possivelmente complementadas 
por um pequeno conhecimento geral sobre a abordagem vigotskiana? A não ser que outros textos adicionais sejam considerados, existe alguma razão para acreditar que um pesquisador tenha uma interpretação melhor dessas palavras do que outro?

\section{CONCEPÇÕES COMUNS DA ZONA DE DESENVOLVIMENTO PRÓXIMO}

A concepção comumente difundida sobre a zona de desenvolvimento próximo pressupõe uma interação em uma tarefa entre uma pessoa mais competente e uma pessoa menos competente, de forma que a pessoa menos competente se torne autonomamente proficiente naquilo que de início era uma tarefa realizada conjuntamente. Nessa concepção geral, três aspectos principais são geralmente destacados ou enfatizados (embora não necessariamente todos os três por um único pesquisador). Para fins de análise, consideraremos que esses três aspectos juntos representam um "tipo ideal”, que será chamado interpretação comum da zona de desenvolvimento próximo. A título de referência, os três aspectos serão chamados de pressuposto da generalidade (ou seja, aplicável para a aprendizagem de todos os tipos de conteúdo); pressuposto da assistência (a aprendizagem depende de intervenções de alguém mais competente); e pressuposto do potencial (propriedade do aprendiz que permite a melhor e mais fácil aprendizagem) ${ }^{6}$.

O primeiro aspecto focaliza a ideia de que uma pessoa é capaz de realizar sozinha certo número de tarefas, mas em colaboração ela pode realizar um número maior. O "escopo de tarefas" realizadas em colaboração é por vezes apresentado como a definição da zona de desenvolvimento próximo (e.g., Berk, 1997, p.248), mas, sem dúvida, isto é equivocado. Mesmo a definição clássica se refere a níveis de desenvolvimento, não a tarefas. Na melhor das hipóteses, o número ou os tipos de tarefas devem ser tomados como indicadores a serem interpretados em relação ao nível de desenvolvimento. Uma questão relacionada é quais tipos de tarefas encerram uma zona de desenvolvimento próximo. Normalmente se assume que a zona de desenvolvimento próximo é aplicável a qualquer tipo

6 O autor gostaria de enfatizar que esses pressupostos descrevem crenças populares, mas incorretas, que não encontram respaldo nos trabalhos publicados de Vigotski. de tarefa de aprendizagem. "Para qualquer campo de habilidade, uma zona de desenvolvimento próximo pode ser criada" (Tharp \& Gallimore, 1998, p.98); ou ainda, em uma concepção "expandida" formulada por Wells (1999), zona de desenvolvimento próximo se refere a "qualquer situação na qual, enquanto participam de uma atividade, indivíduos encontramse no processo de desenvolver o domínio de uma prática ou compreensão de um assunto" (p.133).

$\mathrm{O}$ segundo aspecto enfatiza como um adulto/professor/pessoa mais competente deveria interagir com uma criança. Por vezes esse aspecto é apresentado como a característica definidora: "Podese argumentar que a noção de zona de desenvolvimento próximo é pouco mais significativa do que a de uma situação de aprendizagem apresentada a uma criança, na qual adultos e/ ou crianças mais avançadas têm direta ou indiretamente uma influência positiva sobre a criança" (Gillen, 2000, p.193-194).

O terceiro aspecto focaliza as "propriedades do aprendiz", incluindo as noções de potencial e/ou prontidão de um aprendiz para aprender. Esse aspecto parece inspirar a ideia ou expectativa de que será possível acelerar significativamente ou facilitar a aprendizagem da criança se a zona puder ser corretamente identificada. Temos aqui duas passagens ilustrativas retiradas de recentes discussões de um livrotexto: "é no interior da zona que o potencial de uma pessoa para novas aprendizagens é o mais forte" (Fabes \& Martin, 2001, p.42) ou [a zona de desenvolvimento próximo é] "a expressão de Vygotsky para [designar] o potencial atual de um indivíduo para avanços em seu desenvolvimento intelectual, uma capacidade que não é normalmente mensurada por testes de inteligência convencionais" (LeFrancois, 2001, p. 587). Por vezes esse aspecto é interpretado no sentido de que o ensino que incide na zona de desenvolvimento próximo resulta na forma mais fácil de aprendizagem ou que exige menor esforço da criança (por exemplo: "a zona de desenvolvimento próximo de um estudante é a faixa de níveis de dificuldade para leitura que irão desafiar o estudante sem causar frustração ou perda de motivação" (Base ERIC, 1998).

\section{CRÍTICA DA CONCEPÇÃO COMUM}

A concepção comum de zona de desenvolvimento próximo sustenta ou inspira uma 
visão de perfeição educacional segundo a qual o professor perspicaz (ou "sortudo") é capaz de ajudar uma criança a dominar, sem esforço e de forma prazerosa, qualquer conteúdo que esteja na programação do dia. Com este tipo de concepção, é provável que o leitor alimente expectativas por um capítulo sobre a zona de desenvolvimento próximo que explique: a) como identificar a zona de desenvolvimento próximo de uma criança para cada tarefa de aprendizagem; b) de que forma ensinar para seguramente fazer uso da zona de desenvolvimento próximo e, assim, c) acelerar a aprendizagem de uma forma suave e prazerosa. No entanto, existem alguns problemas nessa visão perfeita.

\section{Pressuposto da generalidade}

Se a intenção de Vigotski era utilizar o conceito para todos os tipos de aprendizagem, então por que não nomeá-lo zona de aprendizagem próxima? Por que o termo desenvolvimento aparece no conceito? $\mathrm{O}$ uso do termo não é acidental. Em diversos textos, Vigotski analisou a forma pela qual as tradições psicológicas existentes concebiam a relação entre aprendizagem e desenvolvimento (1987, p. 194-201; $\left.1935 b^{7}, 1935 d, 1982 b\right)$ e concluiu que existe unidade, mas não identidade entre aprendizagem e processos internos de desenvolvimento (Vygotsky, 1982d, p.123). Vygotsky (1987) distingue o ensino voltado "ao desenvolvimento integral [da criança] do ensino de habilidades técnicas e especializadas como datilografar ou andar de bicicleta" (p.212). Em síntese, o conceito de zona de desenvolvimento próximo não está ligado ao desenvolvimento de habilidades de alguma tarefa particular, mas deve estar relacionada ao desenvolvimento.

\section{Pressuposto da assistência}

Porque um professor competente é importante para a aprendizagem, a noção de zona de desenvolvimento próximo é com frequência utilizada para focalizar a importância de auxílio [de um par] mais competente. No entanto, quando Vigotski introduz o conceito de zona de desenvolvimento próximo em Pensamento e Linguagem, ele considera como um fato bem conhecido que "a criança é sempre capaz de fazer mais e resolver tarefas mais difíceis em colaboração, sob direção ou mediante

7 Ver Van der Veer \& Valsiner (1991, p.329-331), para um resumo. algum tipo de auxílio do que independentemente" (Vygotsky, 1987, p. 209). Mais importante, em sua análise, é explicar por que isso acontece. Em outras palavras, não é a competência em si da pessoa mais conhecedora que se mostra importante; o importante é compreender o significado da assistência em relação à aprendizagem e desenvolvimento da criança.

\section{Pressuposto do potencial}

Vigotski nunca afirmou que a aprendizagem relacionada à zona de desenvolvimento próximo é sempre agradável. Ele dá um exemplo (Vygotsky, 1967, p.16): uma criança disputando uma corrida pode não estar se divertindo, especialmente após perder a corrida, mas ainda assim esta ação pode ser parte da zona de desenvolvimento próximo. Da mesma forma, como será discutido adiante, o potencial não é uma propriedade da criança - como estas formulações são comumente interpretadas mas simplesmente um indício da presença de certas funções em maturação, que podem ser alvo de uma ação interventiva significativa.

A análise acima apresentada pretende levantar dúvidas sobre as interpretações comumente difundidas sobre o conceito de zona de desenvolvimento próximo de Vigotski e justificar a necessidade de considerar mais concretamente o que Vigotski pretendia afirmar com o conceito. Há pelo menos oito textos publicados em que Vigotski usa a expressão zona de desenvolvimento próximo pelo menos uma vez (ver na tabela 1 a lista destes textos, juntamente com algumas das traduções publicadas). A maioria destes textos traz apenas breves comentários sobre o conceito. Uma discussão mais extensa é encontrada no capítulo VI de Pensamento $e$ Linguagem e no capítulo $O$ problema da idade. Em outras palavras, não há um corpo extensivo de material a partir do qual o verdadeiro significado da expressão para Vigotski ou sua definição ou interpretação oficial possa ser encontrado (veja-se a bibliografia referenciada por Rieber, 1999; é possível que alguns dos textos não publicados e ainda inacessíveis de 1933 e 1934 também discutam esse conceito). Uma pessoa poderia ler a maior parte do material listado na tabela $2.1 \mathrm{em}$ poucas horas, especialmente porque vários dos textos contêm consideráveis sobreposições em seu conteúdo. Desse ponto de vista, seria fácil tornar-se um especialista no conceito vigotskiano, sem necessidade de uma discussão interpretativa. 
Tabela 1. Panorama dos textos publicados de Vigotski nos quais o conceito de zona de desenvolvimento próximo é discutido

\begin{tabular}{|c|c|c|c|}
\hline Data & Título & Evento & Fonte da publicação \\
\hline $1933^{8}$ & $\begin{array}{l}\text { Play and its role in the mental } \\
\text { development of the child [Jogo e } \\
\text { seu papel no desenvolvimento } \\
\text { mental da criança] }\end{array}$ & $\begin{array}{l}\text { Transcrição estenográfica de } \\
\text { palestra no Instituto } \\
\text { Pedagógico de Leningrado } \\
\text { A.I.Herzen }\end{array}$ & $\begin{array}{l}\text { Vygotsky, } 1966 \\
\text { Vygotsky, } 1967 \\
\text { Vygotskij, 1982a } \\
\text { Vygotskij, 1983a }\end{array}$ \\
\hline 17 de março, 1933 & $\begin{array}{l}\text { The pedological analysis of the } \\
\text { pedagogical process [A análise } \\
\text { pedológica do processo } \\
\text { pedagógico] }\end{array}$ & $\begin{array}{l}\text { Transcrição estenográfica de } \\
\text { palestra Instituto de } \\
\text { Defectologia Experimental } \\
\text { Epshtein, Moscou }\end{array}$ & $\begin{array}{l}\text { Vygotsky,1935b (resumido } \\
\text { em van der Veer \& Valsiner, } \\
\text { 1991, pp.329-331) }\end{array}$ \\
\hline 20 de maio, 1933 & $\begin{array}{l}\text { Development of everyday and } \\
\text { scientific concepts in school } \\
\text { children [Desenvolvimento de } \\
\text { conceitos cotidianos e científicos } \\
\text { em escolares] }\end{array}$ & $\begin{array}{l}\text { Palestra no Conselho } \\
\text { científico-metodológico, } \\
\text { Instituto Pedológico de } \\
\text { Leningrado }\end{array}$ & $\begin{array}{l}\text { Vygotsky, 1953e } \\
\text { Vygotskij, 1982c }\end{array}$ \\
\hline 23 de dezembro, 1933 & $\begin{array}{l}\text { Dynamics of mental development } \\
\text { of schoolchildren in connection } \\
\text { with teaching [Dinâmica do } \\
\text { desenvolvimento mental de } \\
\text { escolares em conexão com o } \\
\text { ensino] }\end{array}$ & $\begin{array}{l}\text { Transcrição estenográfica de } \\
\text { palestra no Departamento de } \\
\text { Defectologia, Instituto } \\
\text { Pedagógico Bubnov, } \\
\text { Leningrado }\end{array}$ & $\begin{array}{l}\text { Vygotsky, 1935a (resumo } \\
\text { detalhado em van der Veer \& } \\
\text { Valsiner, 1991, pp.336-341) }\end{array}$ \\
\hline $1934^{9}$ & $\begin{array}{l}\text { The problem of teaching and } \\
\text { development during the school age } \\
\text { [O problema do ensino e } \\
\text { desenvolvimento durante a idade } \\
\text { escolar] }\end{array}$ & Manuscrito & $\begin{array}{l}\text { Vygotsky, 1935d } \\
\text { Vygotskij, 1973d } \\
\text { Vygotskij, 1982b } \\
\text { Vygotskij, 1983b } \\
\text { Vygotsky, } 1985\end{array}$ \\
\hline 1934 & $\begin{array}{l}\text { Teaching and development during } \\
\text { the preschool age [Ensino e } \\
\text { desenvolvimento durante a idade } \\
\text { pré-escolar] }\end{array}$ & $\begin{array}{l}\text { Transcrição estenográfica de } \\
\text { palestra na Conferência Russa } \\
\text { de Educação Pré-Escolar }\end{array}$ & $\begin{array}{l}\text { Vygotsky, 1935c } \\
\text { Vygotskij, 1973a } \\
\text { Vygotskij, 1982d } \\
\text { Wygotski, 1987b } \\
\text { Vygotsky, } 1995\end{array}$ \\
\hline $1934^{10}$ & $\begin{array}{l}\text { The problem of age [O problema } \\
\text { da idade] }\end{array}$ & Capítulo de livro manuscrito & $\begin{array}{l}\text { Vygotsky, } 1998 \\
\text { Wygotsky, 1987a }\end{array}$ \\
\hline 1934 & $\begin{array}{l}\text { Thinking and speech (Chapter } \\
6: \text { The development of scientific } \\
\text { concepts) [Pensamento } e \\
\text { linguagem (Capítulo 6: } O \\
\text { desenvolvimento de conceitos } \\
\text { científicos)] }\end{array}$ & Capítulo de livro & Vygotsky, 1987 \\
\hline
\end{tabular}

8 Essa palestra está alocada aqui porque (a) traz uma discussão mínima sobre a ZDP, enquanto (b) uma palestra de 23 de março tem o título "Problema da idade: jogo"; (c) foi intitulada "Preleção de encerramento do seminário"; e (d) uma palestra sobre a pedologia da idade pré-escolar foi proferida em 31 de janeiro no mesmo instituto.

9 Uma versão editada (reduzida) foi publicada em Vygotsky (1956), e traduzida em Vygotski (1963), Wygotski (1987c).

10 Esse texto está relacionado nas Obras Escolhidas (Collected Works) como sendo um registro estenográfico de uma palestra de 23 de março de 1933 (Reiber, 1999, p.297). Isso é um equívoco. Como assinalado em Vygotsky (1998,p.329), este texto é um capítulo escrito, dos arquivos familiares. Valsiner e van der Veer (1993, p.40), apoiando-se na informação trazida nas Obras Escolhidas, reproduzem esse equívoco 
Não obstante, será mais produtivo focar os problemas conceituais que Vigotski tentava abordar quando a zona de desenvolvimento próximo foi introduzida; ou seja, o principal interesse é apresentar uma interpretação que possa ser mais plenamente integrada com outros conceitos teóricos e argumentos que Vigotski estava desenvolvendo em relação à zona de desenvolvimento próximo. Dado que Vigotski foi a fonte dos argumentos identificados hoje como zona de desenvolvimento próximo, parece válido permitir que sua versão seja apresentada a partir de sua própria perspectiva teórica, ao invés de filtrá-la ou refratá-la pelas lentes de posições e preocupações contemporâneas $^{11}$. Essa interpretação mais abrangente do programa de pesquisa de Vigotski não é apresentada aqui por ser uma curiosidade histórica, mas pelo fato de esse modelo teórico merecer continuada investigação, crítica e elaboração. Como primeiro passo, devemos nos certificar de termos alcançado um entendimento razoável sobre como a análise teórica [de Vigotski] é construída e o que ela está buscando alcançar.

\section{A ZONA DE DESENVOLVIMENTO PRÓXIMO NA PERSPECTIVA TEÓRICA DE VIGOTSKI}

A zona de desenvolvimento próximo foi introduzida como parte de uma análise geral do desenvolvimento infantil. Não se trata de um conceito principal ou central na teoria de Vygotsky (1998b) sobre o desenvolvimento infantil, antes, seu papel é evidenciar a importância de um lugar e momento no processo de desenvolvimento da criança. Para compreender esse papel é preciso considerar a perspectiva teórica em que ele aparece, ou seja, é preciso compreender o que Vigotski pretendia dizer com [o conceito de] zona de desenvolvimento próximo em particular. Neste sentido, o leitor pode desenvolver um entendimento mais produtivo da perspectiva teórica, o qual será mais valioso do que uma definição de dicionário desse conceito.

\section{A teoria de Vigotski sobre o desenvolvimento infantil}

Vigotski formulou diversos requisitos ou critérios que deveriam ser atendidos por um modelo do desenvolvimento infantil. Primeiramente, o modelo deve ser explicativo, e não descritivo. Mais especificamente, o modelo deve ser organizado com base em princípios substanciais que possam explicar o

11 Cazden (1996) defende um argumento semelhante em relação à pesquisa sobre escrita inspirada em Vigotski. desenvolvimento "como um processo único de autodesenvolvimento" (Vygotsky, 1998b, p.189). Em segundo lugar, o modelo deveria considerar a criança como um todo, como uma pessoa integral. Em terceiro lugar, a infância deveria ser dividida em períodos, de modo que cada período fosse caracterizado de uma forma unificada e fundamentada em princípios, o que significa que os mesmos princípios explicativos abstratos devem ser empregados para caracterizar cada período (daí a unidade), mas a manifestação concreta das relações abstratas deve ser descoberta e caracterizada para o conteúdo particular de cada período etário.

Para atender a esses requisitos, Vigotski propôs que cada período da infância seja caracterizado abstratamente por uma estrutura psicológica, um conjunto de relações integrais entre funções psicológicas (por exemplo, percepção, memória voluntária, fala, pensamento). Essa estrutura deve refletir a criança como um todo, isto é, como uma pessoa engajada em relações sociais estruturadas com outras pessoas, e não apenas como uma descrição das qualidades da criança, mas também como uma descrição da relação da criança com seu ambiente. Do ponto de vista psicológico, esse todo é descrito como uma estrutura integrada de relações adquiridas por meio de interações materiais. Tal descrição psicológica de uma criança focaliza as inter-relações das funções psicológicas, em vez de considerar funções individuais isoladas. Por exemplo: crianças de dois anos de idade tendem a ser dirigidas mais pelas reações ao que elas podem perceber imediatamente do que pela criação intencional de uma possibilidade imaginada, ou seja, por um pensamento. Neste caso as funções de percepção, pensamento e vontade encontram-se em uma relação particular entre si, de tal forma que a percepção é dominante em relação à vontade e ao pensamento (Vygotsky, 1982d, p.104). A estrutura psicológica se refere às relações estruturais entre um conjunto de funções psicológicas.

$\mathrm{O}$ foco no todo impede uma abordagem metodológica que considere funções específicas sem levar em conta suas relações com o todo. Dessa forma, Vigotski pôde realizar seu objetivo de "compreender o desenvolvimento como um processo que é caracterizado pela unidade dos aspectos materiais e mentais, uma unidade do social e do pessoal ao longo da ascensão da criança a novos estágios do desenvolvimento.” (p.190). Essas duas unidades (material-mental e social-pessoal) são formas alternativas de expressar uma mesma ideia, e ambas são unidades porque a estrutura psicológica da criança 
(o mental, o pessoal) está sempre refletindo uma relação com o social e material. Vigotski se propõe descrever o desenvolvimento das crianças, da primeira infância à adolescência, como uma série de períodos relativamente longos e estáveis (um a quatro anos) entremeados por curtos períodos de crise (ver Mahn, nesse volume ${ }^{12}$, para uma abrangente apresentação do modelo de Vigotski dos períodos etários; ver também Davydov, 1988, p. 63-87). Para explicar a dinâmica causal desse desenvolvimento é preciso esclarecer como e por que há uma mudança qualitativa na estrutura psicológica que é característica para cada período etário. O ponto de partida para a explicação de Vigotski é a relação específica, mas abrangente, da criança com seu ambiente, designada como a situação social de desenvolvimento. "A situação social de desenvolvimento representa o momento inicial para todas as mudanças dinâmicas que ocorrem no desenvolvimento durante um dado período [etário]"; portanto, para estudar a dinâmica de uma idade é preciso primeiramente explicar a situação social de desenvolvimento (Vygotsky, 1998b, p.198).

Cada período etário tem uma nova formação central característica, relativa a quais funções psicológicas se desenvolvem (Vygotsky, 1998b, p.197). Essa nova formação é organizada na situação social de desenvolvimento por uma contradição básica entre as capacidades atuais da criança (que se manifestam nas funções psicológicas verdadeiramente desenvolvidas), as necessidades e desejos das crianças e as demandas e possibilidades do ambiente. Ao tentar superar essa contradição (de forma a poder realizar sua atividade), a criança se engaja em diferentes tarefas concretas e específicas interações, que podem resultar na formação de novas funções ou no enriquecimento de funções já existentes. A nova formação central produzida em um dado período etário é consequência das interações da criança na situação social de desenvolvimento, envolvendo funções psicológicas relevantes que ainda não amadureceram. (Para uma análise concreta do primeiro ano de vida, cf. Vygotsky, 1998a, especialmente pp.215-216; para uma elaboração relacionada e útil da concepção de desenvolvimento de Vygotsky, cf. Schneuwly, 1994, pp.282-284).

Muitas - talvez a maior parte - das ações específicas da criança na vida diária não precisam estar orientadas a confrontar essa contradição (por

12 MAHN, Holbrook. Periods in child development: Vygotsky's perspective. In: KOZULIN, A.; GINDIS, B., AGEYEV, V. S., \& MILLER, S.M. (orgs.), Vygotsky's educational theory in cultural context. Cambridge University Press, 2003. [N.T.] vezes chamada de atividade dominante); contudo, as funções necessárias à transição para um novo período etário, isto é, para uma mudança estrutural na organização das funções, são formadas e elaboradas (em relação à nova formação central) naquelas situações em que a criança se envolve especificamente em ações relevantes para essa contradição. Cada período etário tem uma atividade-guia que é a principal fonte de desenvolvimento no interior daquele período (Vygotsky, 1967, pp.15-16). A noção de "atividade-guia" é uma forma de identificar quais relações específicas na situação social de desenvolvimento são capazes de contribuir para o desenvolvimento das funções que conduzem à reorganização estrutural das funções psicológicas da criança (esta ideia geral foi subsequentemente integrada à teoria da atividade e desenvolvida com maior detalhamento, por exemplo, em El'konin, 1999). A atividade em si mesma não irá desenvolver a criança, mas para realizar a atividade-guia a criança se engaja em ações que servem para desenvolver as funções psicológicas necessárias àquela atividade. A nova formação é um produto - não um pré-requisito de um dado período etário (Vygotsky, 1998b, p.198).

É importante notar que estes períodos etários são compreendidos como material e historicamente construídos: historicamente porque as funções são construídas por meio da história das práticas humanas; e materialmente porque as funções são desenvolvidas como consequência de tarefas e interações com os outros. A situação social de desenvolvimento provê um meio para caracterizar a interação entre formas de prática historicamente construídas e os interesses e ações da criança (que refletem o período etário em que se encontra). Em vez de ser um recebedor passivo de um ambiente objetivo, a criança é seletiva em relação ao que é percebido e lhe interessa. Essa relação muda a cada novo específico período etário, refletindo a estrutura das funções psicológicas daquela idade (ver Lampert Shepel, 1995, p. 429-431, para uma visão relacionada).

Mudanças nas relações históricas inclinariam um pesquisador a prever mudanças nas funções psicológicas (ver Bodrova \& Leong, nesse volume ${ }^{13}$, para uma discussão sobre essa questão em relação à primeira infância). É importante ter clareza de que esses períodos não refletem uma necessidade

13 BODROVA, Elena; LEONG, Deborah. J. Learning and development of preschool children from the Vygotskian perspective. In: KOZULIN, A.; GINDIS, B., AGEYEV, V. S., \& MILLER, S. M. (orgs.), Vygotsky's educational theory in cultural context. Cambridge University Press, 2003. [N.T.] 
biológica (seja por razões genéticas seja por outras causas orgânicas), ainda que o desenvolvimento de funções psicológicas superiores (percepção, memória voluntária, fala, pensamento, etc.) dependa dessas condições naturais. Quando escreve "idade", Vigotski entende esse termo como uma categoria psicológica, e não apenas como uma característica temporal; portanto, na frase "o nível real de desenvolvimento é determinado por aquela idade, aquele estágio ou fase no interior de uma dada idade que a criança experiencia naquele momento" (Vygotsky, 1998b, p.199) pode-se compreender que a expressão "no interior de uma dada idade" refere-se ao período do desenvolvimento. De modo similar, nenhuma das funções psicológicas é "pura" no sentido de uma faculdade ou módulo biologicamente dado; ao contrário, todas elas foram formadas tanto historicamente, no desenvolvimento filogenético das sociedades humanas, quanto individualmente, no desenvolvimento ontogenético de pessoas no interior dessas sociedades.

\section{A zona de desenvolvimento próximo na teoria de Vigotski sobre o desenvolvimento infantil}

Podemos agora utilizar esse modelo do desenvolvimento infantil, como fez Vigotski, para introduzir a ideia de zona de desenvolvimento próximo. A zona de desenvolvimento próximo é utilizada para dois diferentes propósitos na análise do desenvolvimento psicológico (transição de um período do desenvolvimento a outro). Um deles é identificar os tipos de funções psicológicas em maturação (e as interações sociais a elas associadas) que são necessários para a transição de um período do desenvolvimento para o seguinte; e o outro é identificar o estado atual da criança em relação ao desenvolvimento dessas funções necessárias para essa transição. Consideremos esses usos [do conceito] um de cada vez.

Para cada período etário há um grupo de funções psicológicas que estão amadurecendo relacionadas à nova formação central [da idade] e que levarão à reestruturação das funções existentes para a formação de uma nova estrutura. Essa nova formação resulta em uma transição ao período seguinte do desenvolvimento. Para maior clareza, designarei essa constelação tripartite composta pelo período atual do desenvolvimento, pelas funções em maturação e pelo próximo período etário como a zona de desenvolvimento próximo objetiva. Essa zona é "objetiva" no sentido de que ela não se refere a nenhuma criança em particular, mas reflete as funções psicológicas que precisam ser formadas ao longo de um determinado período etário para que se forme o período seguinte.

A zona objetiva não é definida a priori, mas reflete as relações estruturais que são historicamente construídas e objetivamente constituídas no momento histórico em que a criança vive. Pode-se afirmar que a zona objetiva de desenvolvimento próximo para cada período é normativa, na medida em que reflete as demandas e expectativas institucionalizadas que se desenvolveram historicamente em uma particular tradição societária de prática. Por exemplo, espera-se que crianças em idade escolar desenvolvam capacidades de raciocínio com conceitos acadêmicos (isto é, científicos). Indivíduos que não desenvolvem essa capacidade podem ser considerados como detentores de uma estrutura intelectual diferente daquela da maioria dos escolares. O pensamento por conceitos é uma manifestação específica das novas formações dessa idade, as quais Vigotski sugere serem tomada de consciência e voluntariedade ${ }^{14}$.

Todas as principais novas funções que participam ativamente no ensino escolar estão associadas com as novas formações importantes dessa idade, ou seja, com a tomada de consciência e voluntariedade. Estas são as características distintivas de todas as funções psíquicas superiores que se desenvolvem durante esse período (Vygotsky, 1987, p. 213).

Em diferentes condições objetivas - por exemplo, a vida de crianças que trabalhavam em fábricas inglesas no século XIX (ver Marx 1990, capítulo 10, seção 3-6) - a situação social de desenvolvimento seria também diferente; dessa forma, seria necessário caracterizar uma diferente zona objetiva de desenvolvimento próximo para um dado período etário.

Para uma dada zona objetiva de desenvolvimento próximo, é possível (tentar) avaliar o estado atual de desenvolvimento de uma criança singular em relação à zona objetiva. De acordo com a teoria de Vigotski, as funções em maturação são as fontes de mudanças na estrutura interna de um dado período etário. Procedimentos de avaliação devem estar voltados à identificação do atual estado destas funções em maturação. Por serem inadequadas para um

14 As novas funções específicas de uma dada idade (neste caso, tomada de consciência e voluntariedade) podem estar abertas a debate e análise. Para os propósitos desse texto, estamos nos concentrando na formulação conceitual de Vigotski, e não [avaliando] se essa importante asserção particular pode ser corroborada. 
desempenho independente, faz-se necessário identificá-las por meio de procedimentos dinâmicos e interativos que proporcionem indicações para estimar seu grau de desenvolvimento (ver Lidz \& Gindis, nesse volume ${ }^{15}$, para uma discussão extensiva de tais procedimentos). Essa estimativa pode ser entendida em termos relativos - ou seja, o estado atual das funções em maturação relativas às mudanças estruturais que caracterizam o próximo período etário. A extensão em que as funções em maturação da criança estão atingindo a estrutura do próximo período etário configura o que podemos chamar de zona de desenvolvimento próximo subjetiva. A zona subjetiva é chamada de "subjetiva" para indicar que se está falando do desenvolvimento de uma pessoa singular em relação ao próximo período do desenvolvimento formado histórica e objetivamente.

Em síntese, as principais características da análise da zona de desenvolvimento próximo são: (a) a criança como um todo; (b) estrutura interna (relações entre funções psicológicas); (c) desenvolvimento como uma mudança qualitativa nas relações estruturais, (d) advinda das ações da criança na situação social de desenvolvimento (que reflete o que a criança percebe e pelo que se interessa), de modo que (e) cada período etário tem uma atividade-guia/ contradição principal que organiza as ações da criança (no interior da qual operam interesses subjetivos) por meio das quais novas funções se desenvolvem. Zona de desenvolvimento próximo é uma forma de se referir tanto às funções que estão se desenvolvendo ontogeneticamente em um dado (objetivo) período etário quanto ao estado atual de desenvolvimento de uma criança em relação às funções que idealmente precisam ser realizadas (subjetivamente). Neste sentido, a zona de desenvolvimento próximo é uma descoberta tanto teórica quanto empírica.

\section{IDENTIFICANDO (E EXPLICANDO) A ZONA SUBJETIVA DE DESENVOLVIMENTO PRÓXIMO: O PAPEL DA IMITAÇÃO}

O principal problema sobre o qual nos debruçaremos aqui é "como identificar ou avaliar a zona de desenvolvimento próximo de uma determinada criança?’. Várias questões precisam ser consideradas: (a) por que queremos avaliar a zona de

15 LIDZ, Carol S.; GINDIS, Boris. Dynamic assessment of the evolving cognitive functions in children. In: KOZULIN, A.; GINDIS, B., AGEYEV, V. S., \& MILLER, S.M. (orgs.) Vygotsky's educational theory in cultural context. Cambridge University Press, 2003. [N.T.] desenvolvimento próximo? (b) Por que a zona de desenvolvimento próximo existe? (c) Qual o papel da imitação e o da colaboração? (d) Qual é o "tamanho" de uma zona subjetiva [de desenvolvimento próximo]?

Esses diversos aspectos unificam-se em um interesse geral por compreender a dinâmica do desenvolvimento em conexão com uma psicologia voltada à prática (a zona objetiva de desenvolvimento próximo existe por meio da situação social de desenvolvimento).

\section{Por que queremos avaliar a zona de desenvolvimento} próximo?

Como primeiro passo para entender como Vigotski formulou a zona subjetiva de desenvolvimento próximo é importante e necessário compreender por que alguém desejaria fazer tal avaliação. Lembremo-nos de que o interesse de Vigotski era desenvolver uma base teórica para intervenções pedagógicas apropriadas que incluísse princípios para um possível agrupamento de ensino de crianças e a identificação de intervenções específicas para crianças individuais. Intervenções devem estar baseadas em procedimentos de diagnóstico assentados em um entendimento explicativo do atual estado de desenvolvimento de uma criança. Nessa perspectiva, não é aceitável ter apenas indicadores ou sintomas (correlatos) do desenvolvimento psicológico; é preciso servir-se de um entendimento teórico dos processos pelos quais uma pessoa se desenvolve. "Um verdadeiro diagnóstico deve fornecer uma explicação, uma predição e uma base científica para prescrições práticas" (Vygotsky, 1998b, p. 205). Ter uma solução para o problema do diagnóstico equivale a ter uma teoria explicativa do desenvolvimento psicológico. Desse ponto de vista, é possível compreender por que Vygotsky (1998b) relaciona idade, prática e diagnóstico:

\footnotetext{
O problema da idade não é central apenas para todo o desenvolvimento da criança, mas é também a chave de todos os problemas da prática. Este problema é direta e intimamente ligado com o diagnóstico do desenvolvimento da criança relacionado à idade (p.199).
}

Em suma, se compreendermos a dinâmica causal do desenvolvimento da criança, deveremos ser capazes de desenvolver procedimentos para avaliar o atual estado de desenvolvimento de uma pessoa de uma forma que nos dê discernimento sobre o que essa pessoa precisa desenvolver. Vygotsky propõe que a zona de desenvolvimento próximo tomada como um 
princípio diagnóstico "nos permite penetrar na dinâmica causal e nas relações genéticas que determinam o próprio processo de desenvolvimento mental" (p.203). Para realizar o ideal proposto por Vigotski se faz necessária uma explanação teórica sobre por que uma zona subjetiva de desenvolvimento próximo existe e como ela opera de modo a avaliar a zona de desenvolvimento próximo de uma criança (a zona subjetiva de desenvolvimento próximo).

\section{Por que a zona (subjetiva) de desenvolvimento próximo existe?}

Para compreender a explicação de Vigotski sobre a existência da zona de desenvolvimento próximo temos que considerar seu conceito técnico de imitação, em torno do qual sua análise é construída. A habilidade de uma pessoa para imitar, tal como concebida por Vigotski, é a base para uma zona subjetiva de desenvolvimento próximo (a zona objetiva existe por meio da situação social de desenvolvimento). Imitação, na forma como é utilizada aqui, não é um copiar irrefletido de ações (Vygotsky, 1997a, p. 95; 1998b, p. 202). Ao contrário, Vygotsky deseja romper com a visão de que se trata de cópia, dando um novo significado para imitação, o que reflete um novo posicionamento teórico. Nesse novo significado a imitação pressupõe algum entendimento das relações estruturais do problema que está sendo resolvido (1987, p. 210).

Uma criança não é capaz de imitar qualquer coisa (1998b, p. 201; 1987, p. 209). “A imitação é possível somente até o limite e naquelas formas em que é acompanhada pelo entendimento (Vygotsky, 1997a, p. 96). "É bem estabelecido que a criança só pode imitar o que se encontra na zona de suas potencialidades intelectuais" (Vygotsky, 1987, p.209). Imitação referese a "todas as formas de atividade de determinado tipo realizadas pela criança (...) em cooperação com adultos ou com outra criança" (1998b, p. 202) e inclui "tudo o que a criança não pode fazer de forma de independente, mas que pode ser ensinado ou que ela pode fazer sob direção ou em cooperação ou com a ajuda de perguntas-guia" (1998b, p. 202)

O pressuposto crucial é que a imitação é possível porque (a) as funções psicológicas em maturação são ainda insuficientes para sustentar um desempenho independente, mas (b) desenvolveram-se o suficiente para que (c) uma pessoa possa entender como servir-se das ações colaborativas (perguntas-guia, demonstrações, etc.) de outra. A presença dessas funções em maturação é a razão da existência da zona de desenvolvimento próximo. Alternativamente, a zona de desenvolvimento próximo pode ser definida como se referindo àquelas ações intelectuais e funções mentais que a criança é capaz de utilizar em interação, quando o desempenho independente é inadequado.

\section{Maiores esclarecimentos sobre a imitação}

Vigotski provavelmente acreditava haver alguma chance de o termo imitação ser mal compreendido. Ele reconheceu que estava tentando dar um novo significado a um termo que antes havia sido usado em outras perspectivas teóricas. Por exemplo, quando introduz essa ideia em História do desenvolvimento das funções psicológicas superiores (1997a), ele sinaliza a reformulação pretendida "que podemos chamar pela palavra usualmente aceita imitação" e imediatamente tenta prevenir mal-entendidos: "pode parecer que ao falar de imitação (...) estamos retrocedendo aos preconceitos dos quais acabamos de falar" (p.52). Da mesma forma, por vezes ele se refere à imitação "entendida em sentido amplo" (Vygotsky, 1987, p. 210) ou "como definida anteriormente" (1998b, p. 202).

Vygotsky tentava evitar esses desentendimentos, porque considerava a imitação, na forma como ele a estava tentando definir, como "um dos caminhos basilares do desenvolvimento cultural da criança" (1997a, p. 95). O termo imitação nos textos de Vigotski deve ser lido com a ciência de que um se busca um significado técnico especial. Ter sido o conceito elaborado adequadamente ou não constitui uma questão diferente e merece maiores análises. Para os propósitos desse texto, buscaremos compreender o que o autor pretendia com esse conceito.

Vimos que Vigotski utilizou o termo imitação para referir-se a situações nas quais uma criança é capaz de interagir com outros mais competentes em torno de determinadas tarefas que ela não seria capaz de realizar por si mesma, em razão de suas funções psicológicas ainda estarem em maturação. "A criança pode chegar à imitação por meio de ações intelectuais que estão além do que ela é capaz de realizar nas ações mentais ou operações intelectuais independentes e intencionais" (1998b, p. 201). Por exemplo:

Se eu não sei jogar xadrez, eu não serei capaz de jogar uma partida mesmo que um mestre enxadrista me mostre como. Se eu sei aritmética, mas tenho dificuldade em resolver um problema complexo, uma demonstração imediatamente me guiará à minha própria resolução do problema. Por outro lado, se eu não sei matemática avançada, uma demonstração da solução de uma equação diferencial não fará meu pensamento dar um passo sequer nessa direção. Para imitar, deve 
haver alguma possibilidade de passar do que eu consigo fazer para o que eu não consigo (Vygotsky, 1987, p. 209).

Junto com essa tentativa de alterar o significado de imitação, pode-se visualizar no pensamento de Vigotski uma ideia nuclear de uma zona subjetiva de desenvolvimento próximo formulada pelo menos dois anos antes de sua primeira menção registrada: "Resumindo a nova posição da psicologia nessa área, podemos dizer: o círculo de imitação acessível coincide como círculo das possibilidades do desenvolvimento real do animal" (Vygotsky, 1997a, p. 95). Esse pressuposto crítico, para o qual Vygotsky (1998b) afirma haver embasamento oriundo de pesquisas, é subsequentemente formulado de forma mais contundente: há uma "estrita regulação genética entre o que a criança é capaz de imitar e seu desenvolvimento mental"16 (p. 202).

\section{Usando a imitação para avaliar a zona de desenvolvimento próximo}

Podemos agora considerar como o conceito de imitação fornece uma justificativa teórica para avaliar a zona (subjetiva) de desenvolvimento próximo de uma criança. "A área dos processos imaturos, mas em maturação, forma a zona de desenvolvimento próximo de uma criança" (Vygotsky, 1998b, p. 202). Para uma dada criança, essas funções em maturação são mais ou menos desenvolvidas, mas incapazes de sustentar um desempenho independente. $\mathrm{O}$ desempenho independente não é capaz de fornecer evidências sobre quais funções em maturação estão presentes. Se a criança já desenvolveu as funções mentais adequadas será possível o desempenho independente. Em uma situação de interação (colaboração), a criança pode imitar apenas aquilo cujas funções em maturação necessárias estão presentes. Se a criança não tem nenhuma capacidade de imitar, isso deve ser tomado como um indicador de que as funções relevantes não estão presentes. Em outras palavras, a criança só é capaz de aproveitar uma assistência cujo significado possa ser compreendido por ela. Portanto, determinase "o que a criança é capaz de imitar intelectualmente se entendemos esse termo [imitação] como definido anteriormente" (1998b, p. 202).

16 "There is a 'strict genetic pattern between what a child is able to imitate and his mental development". Essa afirmação de Vigotski aparece, na tradução para o espanhol das Obras Escogidas, tomo V, p. 268, da seguinte forma: "La investigación demuenstra la estricta regulación genética entre lo que puede imitar el niño y su desarrollo mental" [N.T.]
Um desempenho assistido bem-sucedido pode ser usado como um indicador do estado de uma função psicológica em maturação:

Falando grosso modo, ao testar os limites da imitação, nós testamos os limites do intelecto de um determinado animal (...). Se queremos aprender quanto um dado intelecto amadureceu no tocante a essa ou aquela função, isso pode ser testado por meio da imitação (Vygotsky, 1997a, p. 96).

Em poucas palavras, nós pedimos a uma criança que resolva problemas que estão além de sua idade mental [aferida pelo desempenho independente] com alguma forma de colaboração e determinamos para quão longe o potencial de colaboração intelectual dessa criança pode ser estendido e quanto ele alcança além de sua idade mental (Vygotsky, 1998b, p. 202).

\section{O propósito da colaboração ao avaliar e caracterizar o tamanho da zona de desenvolvimento próximo}

A interação ou colaboração com uma criança é utilizada para avaliar a zona de desenvolvimento próximo (subjetiva) de uma criança porque proporciona uma oportunidade para a imitação, que é a forma de identificar funções psicológicas em maturação que são ainda inadequadas para o desempenho independente. Isso pode ser visto de modo implícito no seguinte trecho:

Ao aplicarmos o princípio da cooperação para estabelecer a zona de desenvolvimento próximo, obtemos a possibilidade de investigar diretamente $o$ fator mais determinante da maturação mental que deve ser realizada no próximo e subsequentes períodos de seu estágio de desenvolvimento (Vygotsky, 1998b, p. 203).

Vigotski utiliza com frequência o termo colaboração em sua discussão sobre a avaliação da zona de desenvolvimento próximo. O termo não deve ser compreendido como um esforço conjunto e coordenado para avançar, em que o parceiro mais hábil está sempre fornecendo apoio nos momentos em que as funções em maturação são inadequadas. Antes, parece que o termo está sendo adotado para referir-se a qualquer situação em que se está proporcionando à criança alguma interação com outra pessoa relacionada ao problema a ser resolvido. $\mathrm{O}$ foco principal das intervenções colaborativas é encontrar evidências de funções psicológicas em maturação, 
compreendendo que a criança só poderá tirar proveito dessas intervenções porque as funções em desenvolvimento dão suporte a uma capacidade de entender o significado do auxílio que está sendo oferecido.

A julgar pelos textos que estão sendo discutidos aqui, Vigotski não parece ter princípios sistematizados, métodos ou técnicas capazes de indicar como a colaboração deveria ser conduzida por alguém que esteja avaliando uma zona de desenvolvimento. Consideremos esses exemplos de intervenções para avaliar a zona (subjetiva) de desenvolvimento próximo de uma criança. "Nós auxiliamos cada criança por meio de demonstrações, perguntas-guia e pela introdução de elementos da solução da tarefa" (Vygotsky, 1987, p. 209). Aqui segue a lista mais completa que eu fui capaz de encontrar, na qual Vygotsky (1998b) propõe que, após apresentar um problema a uma criança,

\section{nós mostramos à criança como um problema como esse deve ser resolvido e esperamos para ver se ela pode resolver o problema imitando a demonstração; ou então começamos a resolver o problema e pedimos à criança que termine; ou, ainda, propomos que a criança resolva o problema que está além de sua idade mental em cooperação com outra criança mais desenvolvida; ou, finalmente, explicamos à criança o princípio para a solução do problema, fazendo perguntas-guia, analisando o problema para ela, etc (p. 202).}

Não me parece haver uma sequência baseada em princípios nesses tipos de intervenção, nem há nenhuma discussão - aqui ou em qualquer outro lugar onde eu possa encontrá-la - sobre como interpretar respostas a diferentes intervenções em relação à zona de desenvolvimento próximo.

\section{Interpretando os resultados da colaboração}

Embora não dê uma explicação detalhada dos procedimentos para avaliar a zona de desenvolvimento próximo, Vigotski indica como se podem grosso modo interpretar os resultados da solução de problemas em colaboração com uma criança, focalizando os exemplos (presumivelmente) hipotéticos de duas crianças cuja idade mental é definida - mediante procedimentos padronizados de testagem de inteligência - em oito anos (Vygotsky, 1998b, pp.202203; 1987, p. 209). Após a solução assistida de problemas (não especificados) com as crianças, determina-se que com auxílio uma criança resolve problemas que correspondem aos padrões de uma criança de doze anos de idade, enquanto a outra soluciona problemas correspondentes aos padrões de uma criança de nove anos. "No que se refere a processos em maturação, uma criança foi quatro vezes mais longe que a outra" (1998b, p.203).

De maior interesse é o uso que Vigotski faz desse diagnóstico em experimentos de ensino. Se assumimos ser possível, de uma forma aproximada, adotar o procedimento colaborativo e a interpretação descritos no parágrafo anterior, poderemos identificar crianças que têm uma "maior" e "menor" zona de desenvolvimento próximo. É importante notar que esse "tamanho" refere-se à extensão até a qual a criança pode beneficiar-se da colaboração para alcançar um desempenho além do que é determinado pela performance independente em relação às normas do período etário. Não há razões para acreditar que esse "tamanho" seja uma propriedade fixa da criança que permanece constante ao longo dos períodos etários.

Com esse procedimento em mãos, Vigotski pôde realizar experimentos que exploravam as consequências de utilizar seus resultados como um princípio para agrupar crianças com finalidades de ensino. Em um artigo (salvo engano não traduzido nem facilmente acessível), Vygotsky (1935a) descreve um conjunto de experimentos nos quais as crianças são submetidas a testagem e identificadas como detentoras de QI alto ou baixo, bem como de grande ou pequena zona [de desenvolvimento próximo] (determinada pelo tipo de procedimento descrito no parágrafo anterior). Ao se estabelecer o sucesso escolar subsequente, parece que o tamanho da zona de desenvolvimento próximo foi mais preditivo do que o QI; ou seja, crianças com uma maior zona de desenvolvimento próximo, isto é, que dispunham de mais funções em desenvolvimento no momento, tiveram desenvolvimento intelectual similar, a despeito do QI. Do mesmo modo, crianças com uma menor zona de desenvolvimento próximo tiveram um desenvolvimento intelectual semelhante, apesar do QI inicialmente aferido. Em outras palavras: em se tratando de predizer ou compreender o desenvolvimento intelectual futuro, a zona de desenvolvimento próximo deu uma indicação melhor do que a medida do desempenho independente, por focar as funções em desenvolvimento. Um maior número de funções em maturação dá a uma criança melhores oportunidades de se beneficiar do ensino escolar. Um resumo detalhado desse artigo pode ser encontrado em van der Veer \& Valsiner (1991, p. 336-341). 


\section{Lidando com algumas inelegâncias teóricas}

Como um sumário provisório, parece que Vigotski formulou uma lógica teórica geral para avaliar a zona (subjetiva) de desenvolvimento próximo, mas pôde elaborar procedimentos específicos para conduzir a colaboração e interpretar seus resultados apenas de uma maneira aproximada ou inacabada. Ao apresentar o conceito vigotskiano de imitação e o modo como ele é utilizado para investigar a zona (subjetiva) de desenvolvimento próximo, busquei destacar essa lógica teórica e, particularmente, a ideia de que a zona deveria ser definida a partir de uma explicação da natureza do desenvolvimento e de que a avaliação deveria ser dirigida a esses processos. Futuros trabalhos deverão considerar se essa lógica deve ser desenvolvida ou refutada.

Essa distinção entre a lógica teórica e as proposições específicas para concretizá-la constitui um caminho útil para lidar com alguns dos problemas conceituais que emergem ao se tentar delinear a ideia de zona de desenvolvimento próximo em termos de funções em maturação, novas formações e períodos do desenvolvimento, ao mesmo tempo em que se estabelecem relações com a ideia de idade mental e desempenho independente, que são noções provavelmente oriundas de outra teoria do desenvolvimento.

Em seus trabalhos publicados, Vigotski parece aceitar de modo acrítico que o desempenho independente está, de fato, mensurando as funções psicológicas plenamente desenvolvidas. Da mesma forma, ele se refere à idade mental; mas cabe perguntar: como isso pode estar relacionado à ideia de um período do desenvolvimento? Qual a relação entre idade mental e as novas formações necessárias para a transição ao próximo período do desenvolvimento? A noção de imitação está atrelada ao conceito de insight estrutural da Gestalt: isso deveria ser abandonado, revisado ou complementado? Muitas pesquisas contemporâneas têm sido feitas a respeito de interações na solução conjunta de problemas entre um adulto e uma criança: esse trabalho demanda revisão e elaboração da noção um tanto indiferenciada de colaboração de Vigotski? Há muitas outras questões dessa natureza que poderiam ser levantadas, mas elas não poderão ser resolvidas semanticamente, refinando-se definições. Mais importante é ter como foco o delineamento do problema, isto é, a estrutura teórica do argumento geral que está sendo formulado - nesse caso, ter uma explicação do desenvolvimento e um procedimento para o diagnóstico motivado diretamente por essa teoria do desenvolvimento, e não por sintomas de comportamento. É preciso que trabalhos futuros foquem o refinamento $\mathrm{e} a$ elaboração desse programa teórico (por exemplo, a avaliação do desenvolvimento mental deveria ser diretamente voltada às funções específicas que estão se desenvolvendo; é preciso identificar as funções psicológicas necessárias para sustentar a transição ao próximo período do desenvolvimento) com base em qualquer entendimento adicional que tivermos sobre processos de desenvolvimento e aprendizagem.

\section{PERSPECTIVAS E IMPLICAÇÕES (À GUISA DE SÍNTESE)}

- Em termos mais gerais, a ideia de zona de desenvolvimento próximo pretende dirigir a atenção à ideia de que a instrução/ ensino (obuchenie) deve estar focada não nas funções psicológicas já existentes, mas nas funções em desenvolvimento, que são relevantes para o desenvolvimento intelectual geral em direção ao próximo período etário.

- A zona descreve uma relação estrutural, tanto em termos do número, extensão e relações entre funções em desenvolvimento (subjetivo) quanto em relação às funções necessárias para o próximo período etário (objetivo); ou seja, a zona objetiva (quais desenvolvimentos culminarão no próximo período etário) é a mesma para todas as crianças, mas as posições subjetivas de crianças individuais em relação a essa zona objetiva são diferentes (1987, p.209; 1986, p.187; 1982b, p.116-119; para um resumo de 1935 a, ver van der Veer \& Valsiner, 1991, p. 338-339).

- O conteúdo e o significado da zona mudam dependendo do período do desenvolvimento que esteja sendo considerado. O princípio geral para compreender a dinâmica da mudança estrutural é o mesmo, mas é preciso examinar a situação social de desenvolvimento, a estrutura psicológica existente e a próxima estrutura que está sendo formada para que se possa caracterizar apropriadamente a zona objetiva de desenvolvimento próximo para um dado período etário.

- O foco na aprendizagem de conceitos acadêmicos ou escolares em relação à zona de desenvolvimento próximo aparece porque esse desenvolvimento é relevante na idade escolar, não 
porque a zona de desenvolvimento próximo sempre envolve desenvolvimento de conceitos acadêmicos. Outros períodos etários terão outros focos.

- Em relação à idade escolar, a função teórica da pesquisa de Vigotski sobre a zona de desenvolvimento próximo pode ser compreendida como a busca pela identificação de princípios para delinear um modo de conceituar a escolarização com relação à criança como um todo, e não apenas ao desempenho da criança em uma única tarefa (ver Hedegaard, 1990, para um exemplo útil).

- A zona de desenvolvimento próximo não é simplesmente uma forma de se referir ao desenvolvimento por meio da assistência de um outro mais competente. Essa assistência só é significativa em relação a funções em maturação necessárias para a transição ao próximo período etário.

- A zona nunca está localizada unicamente na criança, nem mesmo a zona subjetiva. A zona subjetiva é sempre uma avaliação das capacidades da criança em relação ao modelo teórico do período etário.

\section{Implicações em relação a interpretações contemporâneas}

- Alguns pesquisadores têm caracterizado o conceito de Vigotski como "metafórico" e/ou "heurístico" (por exemplo, Daniels, 2001, p.56; Kovalainen, Kumpulainen \& Vasama, 2001, p.18; Lloyd \& Fernyhough, 1999, p.18; Valsiner, 1998, p.68; Wells, 1999, p.314), ou ainda retórico, descritivo, e não planejado para um desenvolvimento teórico sistemático (Valsiner, 1998, p. 69; Valsiner \& van der Veer, 1993, p.43); mas parece não haver nenhum suporte para essas afirmações.

- Alguns pesquisadores argumentam que a zona de desenvolvimento próximo é criada na interação entre criança e adulto (por exemplo, Davydov, 1998, p.29; Mercer \& Fisher, 1992, p.342; Sternberg \& Grigorenko, 2002, pp.37-38). Esses argumentos merecem maior análise. De acordo com a análise aqui apresentada, a zona de desenvolvimento próximo refere-se às funções em maturação que são relevantes para o próximo período etário e que proporcionam os meios para atuar em situações colaborativas que não poderiam ser alcançadas de forma independente. Essas funções não são criadas na interação; antes, a interação proporciona condições para identificar a existência dessas funções e até que ponto elas se desenvolveram.

Muitas questões restam ainda a discutir:

- O contexto histórico e a base metodológica sobre a qual essas ideias foram desenvolvidas;

- Relações com a teoria do desenvolvimento das funções psicológicas de Vygotsky (1997a);

- Relações com a literatura sobre scaffolding (ver Stone, 1998, para uma boa discussão);

- Problemas nas formulações teóricas de Vigotski;

- Problemas com muitas interpretações contemporâneas da zona de desenvolvimento próximo;

- Implicações para as teorias do ensino e seu planejamento;

- Implicações para o ensino em sala de aula e a diversidade de alunos.

\section{COMENTÁRIO CONCLUSIVO}

Um atrativo da ideia da zona de desenvolvimento próximo em relação a práticas educacionais é que ela fornece uma perspectiva distintiva para conceituar a relação entre aprendizagem e desenvolvimento humanos - uma perspectiva que traz também diferenças fundamentais em relação a muitas visões hoje predominantes sobre essa relação. A despeito do escasso material textual disponível produzido por Vigotski sobre a zona de desenvolvimento próximo, interpretações dessa ideia têm sido suficientes para estimular uma série de pesquisas e reflexões buscando esclarecer e elaborar essa ideia básica. Isso gerou uma diversidade de interpretações e variações, a qual possivelmente continuará existindo nas próximas décadas, dadas a natureza relativamente pouco especificada da formulação original e a variedade de situações práticas nas quais a ideia vem sendo utilizada. Essas variações e elaborações, juntamente com a avaliação crítica sobre elas, são uma parte necessária do processo científico necessário para refinar a zona de desenvolvimento próximo como um conceito para compreender e desenvolver práticas educacionais. Não há razões para se defender a infalibilidade ou suficiência dos argumentos e empreendimentos de Vigotski quanto ao conceito de zona de desenvolvimento próximo, mas cumpre colocar as seguintes observações: (a) Vigotski estava tentando levantar uma série de questões que não haviam sido confrontadas adequadamente na literatura 
contemporânea referente a esse conceito; (b) muitas das "resoluções" ou "novos desenvolvimentos" que diversos autores têm proposto parecem configurar uma diluição dessas questões teóricas gerais, ao invés de trazerem esclarecimento ou aprofundamento; e (c) muitos dos argumentos, críticas e preocupações que têm sido levantadas são nitidamente equivocadas ou não orientadas pela perspectiva teórica de Vigotski. Pessoas que desejam utilizar o conceito de zona de desenvolvimento próximo deveriam, pelo menos, tentar compreender os problemas teóricos e conceituais sobre os quais Vigotski se debruçava quando formulou esse conceito.

Agora, como mais textos de Vigotski são facilmente acessíveis, não há desculpas para continuar utilizando interpretações limitadas ou distorcidas do conceito. Parece mais apropriado utilizar o termo zona de desenvolvimento próximo para referir-se ao fenômeno sobre o qual Vigotski escreveu e encontrar outros termos (por exemplo, instrução assistida, scaffolding) para referir-se a práticas como o ensino de um determinado conceito, habilidade, e assim por diante. Não se trata de negar a importância e significado de outras investigações (por exemplo sobre solução conjunta de problemas, avaliação dinâmica de capacidades intelectuais), mas de indicar que não há mérito científico em referir-se a esses fenômenos como zona de desenvolvimento próximo a não ser que se tenha uma teoria do desenvolvimento à qual tais avaliações possam ser relacionadas. É precisamente nesse ponto que podemos constatar, por contraste, que a maioria dos trabalhos que aludem ao conceito zona de desenvolvimento próximo não trazem essa teoria do desenvolvimento, nem mesmo implicitamente. Esse aspecto merece ser investigado de modo mais intensivo.

\section{REFERÊNCIAS}

Berk, L. (1997). Child development ( $4^{\text {th }}$ ed.). Boston: Allyn \& Bacon.

Cazden, C. B. (1996). Selective traditions: Readings of Vygotsky in writing pedagogy. In D. Hicks (Ed.), Discourse, learning, and schooling (pp. 165-185). Cambridge: Cambridge University Press.

Daniels, H. (2001). Vygotsky and pedagogy. London: Routledge Falmer.

Davydov, V. V. (1988). Problems of the child's mental developmental. Soviet Education, 30(8), 44-97.

Davydov, V. V. (1998). The concept of developmental teaching. Journal of Russian and East European Psychology, 36(4), 11-36.
Dunn, W. E., \& Lantolf, J. P. (1998). Vygotsky's zone of proximal development and Krashen's "i +1": Incommensurable constructs; incommensurable theories. Language Learning, 48, 411-442.

El'konin, D. B. (1999). Toward the problem of stages in the mental development of children. Journal of Russian and East European Psychology, 37(6), 11-30.

Exner, C. E. (1984). The zone of proximal development in inhand manipulation skills of nondysfunctional 3- and 4year-old children. American Journal of Occupational Therapy, 38, 446-451.

Fabes, R., \& Martin, C. L. (2001). Exploring development through childhood. Boston: Allyn \& Bacon.

Gholson, S. A. (1998). Proximal positioning: A strategy of practice in violin pedagogy. Journal of Research in Music Education, 46, 535-545.

Gillen, J. (2000). Versions of Vygotsky. British Journal of Educational Studies, 48, 183-198.

Hedegaard, M. (1990). The zone of proximal development as a basis for instruction. In L. Moll (Ed.), Vygotsky and education: Instructional implications and applications of sociohistorical psychology (pp. 349-371). Cambridge: Cambridge University Press.

Holaday, B., La Montagne, L., \& Marciel, J. (1994). Vygotsky's zone of proximal development: Implications for nurse assistance of children's learning. Issues in Comprehensive Pediatric Nursing, 17, 15-27.

Hung, D. W. L. (2001). Design principles for web-based learning: Implications for Vygotskian thought. Educational Technology, 41(3), 33-41.

Jones, G. M., Rua, M. J., \& Carter, G. (1998). Science teachers' conceptual growth within Vygotsky's zone of proximal development. Journal of Research in Science Teaching, 35, 967-985.

Kilgore, D. W. (1999). Understanding learning in social movements: A theory of collective learning. International Journal of Lifelong Education, 18, 191-202.

Kovalainen, M., Kumpulainen, K., \& Vasama, K. (2001). Orchestrating classroom interaction in a community of inquiry: Modes of teacher participation. Journal of Classroom Interaction, 36(2), 17-28.

Lampert Shepel, E. N. (1995). Teacher self-identification in culture from Vygotsky's developmental perspective. Anthropology \& Education Quarterly, 26, 425-442.

Lantolf, J. P., \& Pavlenko, A. (1995). Sociocultural theory and second language acquisition. Annual Review of Applied Linguistics, 15, 108-124.

LeFrancois, G. (2001). Of children: An introduction to child and adolescent development (9th ed.). Belmont, CA: Wadsworth/Thomsen.

Leiman, M., \& Stiles, W. B. (2001). Dialogical sequence analysis and the zone of proximal development as conceptual enhancements to the assimilation model: The case of Jan revisited. Psychotherapy Research, 11, 311330.

Lloyd, P., \& Fernyhough, C. (Eds.), (1999). Lev Vygotsky: Critical assessments (Vol. 3: The zone of proximal development). London: Routledge. 
Lyons, B. G. (1984). Defining a child's zone of proximal development: Evaluation process for treatment planning. American Journal of Occupational Therapy, 38, 446-451.

Marx, K. (1990). Capital: Vol. 1 (B. Fowkes, Trans.). Harmondsworth, England: Penguin. (Original work published 1867).

McKechnie, L. (1997). Vygotsky's zone of proximal development - a useful theoretical approach for research concerning children, libraries, and information. Journal of Youth Services in Libraries, 11, 66-70.

Mercer, N., \& Fisher, E. (1992). How do teachers help children to learn? An analysis of teacher's interventions in computer-based activities. Learning and Instruction, 2, 339-355.

Palinscar, A. S. (1998). Keeping the metaphor of scaffolding fresh: A response to C. Addison Stone's "The metaphor of scaffolding: Its utility for the field of learning disabilities". Journal of Learning Disabilities, 31, 370373.

Rieber, R. W. (Ed.). (1999). The collected works of L. S. Vygotsky: (Vol. 6. Scientific legacy). New York: Kluwer Academic/Plenum.

Schneuwly, B. (1994). Contradiction and development: Vygotsky and paedology. European Journal of Psychology and Education, 9, 281-291.

Smith, A. B. (1993). Early childhood educare: Seeking a theoretical framework in Vygotsky's work. International Journal of Early Years Education, 1(1), 47-61.

Spouse, J. (1998). Scaffolding student learning in clinical practice. Nurse Education Today, 18, 259-266.

Sternberg, R. J., \& Grigorenko, E. L. (2002). Dynamic testing: The nature and measurement of learning potential. Cambridge: Cambridge University Press.

Stone, C. A. (1998). The metaphor of scaffolding: Its utility for the field of learning disabilities. Journal of Learning Disabilities, 31, 344-364.

Tappan, M. B. (1998). Moral education in the zone of proximal development. Journal of Moral Education, 27, 141-160.

Tharp, R., \& Gallimore, R. (1998). A theory of teaching as assisted performance. In D. Faulkner, K. Littleton, \& M. Woodhead (Eds.), Learning relationships in the classroom (pp. 93-109). London: Routledge.

Torres, M. N. (1996, October 21-24). Teacher-researchers in the "zone of proximal development": Insights for teacher education. Paper presented at the International Conference: "A Cultural-Historical Approach to the Study of Education: Centenary of Lev S. Vygotsky", Moscow.

Valsiner, J. (1998). The guided mind. Cambridge, MA: Harvard University Press.

Valsiner, J., \& van der Veer, R. (1993). The encoding of distance: The concept of the zone of proximal development and its interpretations. In R. R. Cocking \& K. A. Renninger (Eds.), The development and meaning of psychological distance (pp. 35-62). Hillsdale, NJ: Erlbaum.
Van der Veer, R., \& Valsiner, J. (1991). Understanding Vygotsky: A quest for synthesis. Oxford: Blackwell.

Vygotski, L. S. (1963). Learning and mental development at school age (J. Simon, Trans.). In B. Simon \& J. Simon (Eds.), Educational psychology in the U.S.S.R. (pp. 2134). London: Routledge \& Kegan Paul.

Vygotskij, L. S. (1973a). Apprendimento e sviluppo nell'età prescolare. In Lo sviluppo psichico del bambino (pp. 126143). Roma: Riuniti. (Original publicado em 1935)

Vygotskij, L. S. (1973b). Il problema dell'apprendimento e dello sviluppo intellettuale nell'età scolastica. In Lo sviluppo psichico del bambino (pp. 144-164). Roma: Riuniti. (Original publicado em 1935)

Vygotskij, L. S. (1982a). Legen og dens rolle i barnets psykiske udvikling. [Play and its role in the child's psychological development] (N. Måge, Trans.). In Om barnets psykiske udvikling: En artikelsamling (pp. 5071). Copenhagen: Nyt Nordisk Forlag Arnold Busck. (Original publicado em 1935).

Vygotskij, L. S. (1982b) . Spørgsmålet om undervisningen og den intellektuelle udvikling i skolealderen [The question about teaching and its intellectual development in the school age] (N. Måge, Trans.). In Om barnets psykiske udvikling: En artikelsamling (pp. 105-121). Copenhagen: Nyt Nordisk Forlag Arnold Busck. (Original publicado em 1935).

Vygotskij, L. S. (1982c). Udvikling af dagligdags og videnskabelige begreper i skolealderen. [Development of everyday and academic concepts in the school age.] (N. Måge, Trans.). In Om barnets psykiske udvikling: En artikelsamling (pp. 125-149). Copenhagen: Nyt Nordisk Forlag Arnold Busck. (Original publicado em 1935).

Vygotskij, L. S. (1982d). Undervisning og udvikling i førskolealderen. [Teaching and development in the preschool age.] (N. Måge, Trans.). In Om barnets psykiske udvikling: En artikelsamling (pp. 89-104). Copenhagen: Nyt Nordisk Forlag Arnold Busck. (Original publicado em 1935).

Vygotskij, L. S. (1983a). Il giuoco e la sua funzione nello sviluppo psichico del bambino (R. Plantone, Trans.). In L. Mecacci (Ed.), Vygotskij: Antologia di scritti (pp. 227253). Bologna: Il Mulino. (Original publicado em 1966)

Vygotskij, L. S. (1983b). Il problema dell'istruzione e dello sviluppo mentale in età scolare. In L. Mecacci (Ed.), Vygotskij: Antologia di scritti (pp. 255-277). Bologna: Il Mulino. (Original publicado em 1935)

Vygotsky, L. S. (1933, 23 December). K voprosy o dinamike umstvennogo razvitie normal'nogo $i$ nenormal'nogo rebenka. Unpublished stenographic transcript of lecture at the Bubnov Pedagogical Institute, Moscow.

Vygotsky, L. S. (1935a). Dinamika umstvennogo razvitiza shkol'nika $\mathrm{v}$ svjazi $\mathrm{s}$ obucheniem. In Umstvennoie razvitie detei $v$ protsesse obuchenia (pp. 33-52). Moscow/Leningrad: Gosudarstvennoie Uchebnopedagogicheskoie Izdatel'stvo.

Vygotsky, L. S. (1935b). O pedologicheskom analize pedagoheskogo processa. In Umstvennoie razvitie detei $v$ protsesse obuchenia (pp. 116-134). Moscow/Leningrad: 
Gosudarstvennoie

Uchebno-pedagogicheskoie Izdatel'stvo.

Vygotsky, L. S. (1935c). Obuchenie i razvitie v doshykol'nom vozraste. In Umstvennoie razvitie detei $v$ protsesse obuchenia (pp. 20-32). Moscow/Leningrad: Gosudarstvennoie Uchebnopedagogicheskoie Izdatel'stvo.

Vygotsky, L. S. (1935d). Problema obuchenia i umstvennoe razvitie v shkol'nom vozraste. In Umstvennoie razvitie detei $v$ protsesse obuchenia (pp. 3-19). Moscow/Leningrad: Gosudarstvennoie Uchebnopedagogicheskoie Izdatel'stvo.

Vygotsky, L. S. (1935e). Razvitie zhiteiskikh i nauchnykh ponyatii $\mathrm{v}$ shkol'nom vozraste. In Umstvennoie razvitie detei $v$ protsesse obuchenia (pp. 96-115). Moscow/Leningrad: Gosudarstvennoie Uchebnopedagogicheskoie Izdatel'stvo.

Vygotsky, L. S. (1935f). Umstvennoie razvitie detei $v$ protsesse obuchenia. Moscow/Leningrad: Gosudarstvennoie Uchebno-pedagogicheskoie Izdatel'stvo.

Vygotsky, L. S. (1956). Obuchenijia i umstvennoe razvitie v shkol'nom vozraste. In A. N. Leontiev \& A. R. Luria (Eds.), Izbrannye psikhologicheskie issledovanija (pp. 438-452). Moscow: Izdatel'stov APN RSFSR. (Original publicado em 1934)

Vygotsky, L. S. (1962). Thought and language (E. Hanfmann \& G. Vakar, Eds. and Trans.). Cambridge, MA: MIT Press. (Original publicado em 1934)

Vygotsky, L. S. (1966). Igra i ee rol' v psikhicheskom razvitti rebenka. Voprosy Psikhologii, 6, 62-76.

Vygotsky, L. S. (1967). Play and its role in the mental development of the child. Soviet Psychology, 5(3), 6-18.

Vygotsky, L. S. (1978). Interaction between learning and development (M. Lopez-Morillas, Trans.). In M. Cole, V. John-Steiner, S. Scribner, \& E. Souberman (Eds.), Mind in society: The development of higher psychological processes (pp. 79-91). Cambridge, MA: Harvard University Press.

Vygotsky, L. S. (1985). La problème de l'enseignement et du développement mental à l'âge scolaire (C. Haus, Trans.). In B. Schneuwly \& J.-P. Bronckart (Eds.), Vygotsky aujourd'hui (pp. 95-117). Neuchâtel: Delachaux \& Niestlé. (Original publicado em 1935)

Vygotsky, L. S. (1986). Thought and language (A. Kozulin, Trans.). Cambridge, MA: MIT Press. (Original publicado em 1934)

Vygotsky, L. S. (1987). Thinking and speech (N. Minick, Trans.). In R. W. Rieber \& A. S. Carton (Eds.), The collected works of L. S. Vygotsky: Vol. 1. Problems of general psychology (pp. 39-285). New York: Plenum Press. (Original publicado em 1934)

Vygotsky, L. S. (1995). Apprentissage et développement à l'age prescolaire. Société française, 2/52, 35-46.
Vygotsky, L. S. (1997a). The collected works of L. S. Vygotsky: (Vol. 4. The history of the development of higher mental functions). (M. Hall, Trans.; R. W. Rieber, Ed.). New York: Plenum Press. (Original publicado em 1931).

Vygotsky, L. S. (1998a). Infancy (M. Hall, Trans.). In R. W. Rieber (Ed.), The collected works of L. S. Vygotsky: (Vol. 5. Child psychology) (pp. 207-241). New York: Plenum Press. (Original publicado em 1933-1934)

Vygotsky, L. S. (1998b). The problem of age (M. Hall, Trans.). In R. W. Rieber (Ed.), The collected works of $L$. S. Vygotsky: (Vol. 5. Child psychology) (pp. 187-205). New York: Plenum Press. (Original publicado em 19331934)

Vygotsky, L.S. (1997b). The historical meaning of the crisis in psychology: A methodological investigation ( $R$. van der Veer, Trans.). In R.W. Reiber \& J. Wollock (Eds.), The collected works of L.S. Vygotsky: (Vol. 3. Problems of the theory and history of psychology) (pp. 233-343). New York: Plenum Press. (Original publicado em 1927)

Wells, G. (1999). Dialogic inquiry: Towards a sociocultural practice and theory of education. Cambridge: Cambridge University Press.

Wertsch, J. W. (1984). The zone of proximal development: Some conceptual issues. In B. Rogoff \& J. V. Wertsch (Eds.), New directions for child development: No. 23. Children's learning in the "zone of proximal development" (pp. 7-18). San Francisco: Jossey-Bass.

Wilson, A., \& Weinstein, L. (1996). The transference and the zone of proximal development. Journal of the American Psychoanalytic Association, 44, 167-200.

Wygotski, L. S. (1987a). Das Problem der Altersstufen. In J. Lompscher (Ed.), Lew Wygotski: Ausgewählte Schriften: Band 2. Arbeiten zur psychischen Entwicklung der Persönlichkeit (pp. 53-90). Köln: Pahl-Rugenstein Verlag. (Original publicado em 1934)

Wygotski, L. S. (1987b) Unterricht und Entwicklung im Vorschulalter. In J. Lompscher (Ed.), Lew Wygotski: Ausgewählte Schriften: Band 2. Arbeiten zur psychischen Entwicklung der Persönlichkeit (pp. 255-270). Köln: Pahl-Rugenstein Verlag. (Original publicado em 1934).

Wygotski, L. S. (1987c) Unterricht und geistige Entwicklung im Schulalter. In J. Lompscher (Ed.), Lew Wygotski: Ausgewählte Schriften: Band 2. Arbeiten zur psychischen Entwicklung der Persönlichkeit (pp. 287-306). Köln: Pahl-Rugenstein Verlag. (Original publicado em 1956)

Recebido em 14/01/2011 Aceito em 24/01/2012

Endereço para correspondência:

Juliana Campregher Pasqualini. UNESP, Departamento de Psicologia, Av. Eng. Luiz Edmundo Carrijo Coube, 14-01, CEP 17033-360,Bauru/SP.E-mail: jupasqualini@uol.com.br. 